\title{
Structure and Receptor Binding Specificity of Hemagglutinin H13 from Avian Influenza A Virus H13N6
}

\author{
Xishan Lu, ${ }^{\text {a,b }}$ Jianxun Qi, ${ }^{b}$ Yi Shi, ${ }^{b, f}$ Ming Wang, ${ }^{a}$ David F. Smith, ${ }^{c}$ Jamie Heimburg-Molinaro, ${ }^{c}$ Yanfang Zhang, ${ }^{e}$ James C. Paulson, ${ }^{d}$

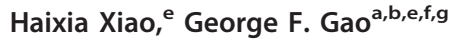 \\ College of Veterinary Medicine, China Agricultural University, Beijing, Chinaa; CAS Key Laboratory of Pathogenic Microbiology and Immunology, Institute of Microbiology,

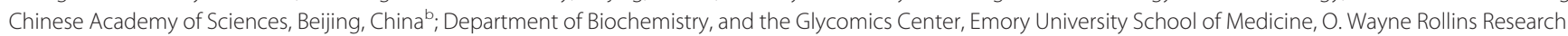 \\ Center, Atlanta, Georgia, USAc; Department of Cell and Molecular Biology, The Scripps Research Institute, La Jolla, California, USA ${ }^{\text {d }}$ Laboratory of Protein Engineering and \\ Vaccines, Tianjin Institute of Industrial Biotechnology, Chinese Academy of Sciences, Tianjin, China ${ }^{\text {; }}$ Research Network of Immunity and Health, Beijing Institutes of Life \\ Science, Chinese Academy of Sciences, Beijing, Chinaf; Institute for Viral Disease Control and Prevention, Chinese Center for Disease Control and Prevention, Beijing, \\ China $^{9}$
}

Interspecies transmission (host switching/jumping) of influenza viruses is a key scientific question that must be addressed. In addition to the vigorous research on highly pathogenic avian influenza viruses (HPAIVs), studies of the mechanism of interspecies transmission of low-pathogenic avian influenza viruses (LPAIVs) could also provide insights into host tropism and virulence evolution. Influenza A viruses harboring hemagglutinin (HA) H13 (e.g., H13N6) are LPAIVs. In this study, soluble H13 HA glycoprotein was purified, and its receptor binding activity was characterized. The results revealed that $\mathrm{H} 13$ exclusively binds the avian $\alpha 2$-3-linked sialic acid receptor; no binding to the mammalian $\alpha 2-6$-linked sialic acid receptor was detected. Furthermore, the molecular basis of the $\mathrm{H} 13$ receptor binding specificity was revealed by comparative analysis of the crystal structures of both receptor-bound $\mathrm{H} 13$ and $\mathrm{H} 5 \mathrm{HAs}$, which might be contributed by the hydrophobic residue V186. Work with an H13N186 mutant confirmed the importance of V186 in the receptor binding specificity of H13 HA, which shows that the mutant protein reduced the binding of an avian receptor analog but increased the binding of a human receptor analog. Detailed structural analysis also demonstrated that the conserved binding sites of the recently well-studied broadly neutralizing human monoclonal antibodies targeting the HA2 domain are found in H13. Our results expand our understanding of virulence evolution, receptor binding preference, and species tropism of the LPAIVs and HPAIVs.

T here are three types of influenza virus: A, B, and C. Influenza A viruses account for all known major epidemics and pandemics, though some mild epidemics of influenza B virus have been recorded (1-4). Influenza A viruses are classified into subtypes according to their two surface glycoproteins, hemagglutinin (HA) and neuraminidase (NA) $(5,6)$. For HA, which functions in sialic acid receptor binding and membrane fusion during virus infection, 16 functional antigenic subtypes ( $\mathrm{H} 1$ to $\mathrm{H} 16)$ and one bat HA homolog (H17) have been reported (7-10). For NA, the receptor-destroying enzyme that removes sialic acid from the virus and cellular glycoproteins to release newly made virus from the infected cells, there are 9 functional antigenic subtypes (N1 to N9) and one bat NA homolog (N10) (9-11). Influenza A virus infects a broad spectrum of species, including many animals, humans, and birds (5). Interspecies transmission (host switching/jumping) is a major virulence factor for influenza viruses. In general, human viruses preferentially interact with an $\mathrm{N}$-acetyl sialic acid attached to galactose with an $\alpha 2-6$ linkage, whereas avian viruses mostly bind to $N$-acetyl sialic acid attached to galactose with an $\alpha 2-3$ linkage (12). This specificity corresponds, to a degree, with the availability and density of such glycans at the principle sites of infection in the host. For example, $\alpha 2$-3-linked glycans predominate in the intestinal tracts of ducks, where viral replication generally occurs during natural infection $(13,14)$, while in humans, $\alpha$-2-6-linked glycans predominate in the upper respiratory tract (15-17).

The $17 \mathrm{HA}$ subtypes are divided into two groups based on phylogenic analysis. Group 1 can be further divided into three clades (containing H8, H9, and H12; H1, H2, H5, H6 and H17; and $\mathrm{H} 11, \mathrm{H} 13$, and $\mathrm{H} 16$ ), and group 2 includes two clades (containing $\mathrm{H} 3, \mathrm{H} 4$, and $\mathrm{H} 14$ and $\mathrm{H} 7, \mathrm{H} 10$, and $\mathrm{H} 15)(18,19)$. Since the first HA structure was solved in 1981 (20), nine of the 17 known HAs (H1, H2, H3, H5, H7, H9, H14, H16, and H17) have been crystallized $(19,21-28)$, and structural correlates of these subtypes have been made from comparisons of the three-dimensional structures of representative HAs from different clades $(9,19)$.

To date, only three HA subtypes have adapted to cause pandemics in humans: H1N1 in 1918 and most recently 2009, H2N2 in 1957, and H3N2 in 1968 (18). Other subtypes (e.g., H5N1, H6N1, H7N2, H7N7, and H9N2) have caused epidemics in domestic poultry in certain areas of the world (29). Moreover, some viruses from poultry involving subtypes $\mathrm{H} 5, \mathrm{H} 7$, and $\mathrm{H} 9$ have resulted in sporadic infections with high fatality in humans, but their low transmissibility among humans has prevented any new pandemics or epidemics (30-32). However, two recent papers report that only a few mutations in the HA protein give the $\mathrm{H} 5 \mathrm{~N} 1$ viruses the ability to spread through the air between ferrets (33,

\footnotetext{
Received 24 January 2013 Accepted 31 May 2013

Published ahead of print 12 June 2013

Address correspondence to George F. Gao, gaof@im.ac.cn.

Supplemental material for this article may be found at http://dx.doi.org/10.1128

/JVI.00235-13.

Copyright @ 2013, American Society for Microbiology. All Rights Reserved.

doi:10.1128/JVI.00235-13
} 
34). Evidence was also provided that the wild H5N1 virus could potentially evolve to spark a pandemic on its own $(33,34)$.

Generally speaking, many scientists focus on the highly pathogenic $\mathrm{H} 5 \mathrm{~N} 1$ virus, and less attention is paid to other avian HA subtypes (e.g., H13 and H16), which are commonly seen in some gulls and shorebirds (35). However, these avian subtypes still have the potential to cross species barriers to infect humans and thus are a major concern for public health. Investigation of the receptor binding properties of these avian subtypes could contribute to the understanding of host range switching during virus transmission.

The H13 subtype virus was first isolated in 1977 from gulls (H13N6) in the United States (36) and has subsequently been detected primarily in gulls and shorebirds as a virus with low pathogenicity (37). To better understand the receptor binding specificity of this subtype, we performed a series of receptor binding experiments, including surface plasmon resonance (SPR) analysis and glycan microarray analysis, and further determined the three-dimensional atomic structure of $\mathrm{H} 13$ and that of its complexes with an avian receptor analog (LSTa). We demonstrated here that $\mathrm{H} 13$ specifically binds the avian receptor analog but not the human receptor. Comparative analysis of the crystal structures of both receptor-bound $\mathrm{H} 13$ and $\mathrm{H} 5 \mathrm{HAs}$ revealed that this specificity might be contributed by the hydrophobic residue V186. We generated the H13N186 mutant and found that this mutant protein reduced the binding of the avian receptor analog but increased the binding of the human receptor analog. These results provide the structural basis for the receptor binding specificity of $\mathrm{H} 13$ and important insight into the interaction of H13 with avian hosts.

\section{MATERIALS AND METHODS}

H13 cloning, expression, and purification. Highly stable and pure H13 protein was prepared using previously established methods (38), with slight modifications, using the Bac-to-Bac baculovirus expression system (Invitrogen). The cDNA corresponding to residues 11 to 329 (HA1) and 1 to 176 (HA2) of the ectodomain of HA from the A/gull/Maryland/704/ 1977 (H13N6) virus was cloned into the baculovirus transfer vector pFastBac1 (Invitrogen), with a GP67 signal peptide at the N terminus, a thrombin cleavage site, a trimerizing sequence, and $\mathrm{a} \mathrm{His}_{6}$ tag at the $\mathrm{C}$ terminus. The recombinant baculovirus was prepared based on the manufacturer's protocol (Invitrogen). H13 and H13N186 proteins were obtained from infected Hi5 insect cells using previously reported purification methods (38).

SPR analysis. Ion-exchange chromatography-purified H13 and $\mathrm{H} 13 \mathrm{~N} 186$ proteins were subjected to thrombin digestion $(3 \mathrm{U} / \mathrm{mg}$ protein overnight at $4^{\circ} \mathrm{C}$ ) and purified by gel filtration chromatography using standard phosphate-buffered saline (PBS) with $0.005 \%$ Tween 20 (PBST) as the running buffer. The affinity and kinetics of the binding of soluble HAs to receptor analogs were measured at $25^{\circ} \mathrm{C}$ on a BIAcore 3000 instrument using streptavidin chips (SA chips; Biacore) by SPR. Two biotinylated receptor analogs, the $\alpha-2-6$ glycans $\left\{6^{\prime} \mathrm{S}-\mathrm{Di}-\mathrm{LN}\right.$ [Neu5Aca26(Galb1-4GlcNAcb1-3)2b-SpNH-LC-LC-biotin] $\}$ and the $\alpha-2-3$ glycans $\{3$ 'S-di-LN [Neu5Aca2-3(Galb1-4GlcNAcb1-3)2b-SpNH-LC-LC-biotin] $\}$ were kindly provided by the Consortium for Functional Glycomics. The $\alpha-2-6$ glycans and $\alpha-2-3$ glycans were immobilized on a CM5 chip with 500 response units. H13 HA protein $(20,10,5,2.5,1.25,0.63,0.31$, or $0 \mu \mathrm{M}$ ) was allowed to flow through the chip, and the response units were recorded. In a comparable assay, $\mathrm{H} 13$ and $\mathrm{H} 13 \mathrm{~N} 186$ proteins were elevated to a higher concentration $(100 \mu \mathrm{M})$. The data were analyzed using BIAevaluation software and fitted to a 1:1 binding model using HA monomer for calculating molecular weight.

Glycan microarray analysis. Glycan microarray analysis was performed using $20 \mathrm{mM}$ Tris- $\mathrm{HCl}$ ( $\mathrm{pH} 8.0$ ) and $150 \mathrm{mM} \mathrm{NaCl}$ as the running
TABLE 1 Data collection and refinement statistics

\begin{tabular}{|c|c|c|}
\hline \multirow[b]{2}{*}{ Parameter } & \multicolumn{2}{|l|}{ Value $^{a}$ for: } \\
\hline & $\mathrm{H} 13$ & H13-LSTa \\
\hline \multicolumn{3}{|c|}{ Data collection statistics } \\
\hline Space group & P1 & P1 \\
\hline \multicolumn{3}{|l|}{ Cell dimensions } \\
\hline$a, b, c(\AA)$ & $75.11,77.06,76.47$ & $75.64,76.80,76.38$ \\
\hline$\alpha, \beta, \gamma\left({ }^{\circ}\right)$ & $85.50,82.55,87.37$ & $85.60,82.67,87.52$ \\
\hline Resolution $(\AA)$ & $50-2.50(2.59-2.50)$ & $50-2.60(2.69-2.60)$ \\
\hline$R_{\text {merge }}$ & $0.086(0.588)$ & $0.106(0.586)$ \\
\hline$I / \sigma I$ & $15.0(2.1)$ & $11.4(3.5)$ \\
\hline Completeness (\%) & $98.0(97.6)$ & $95.7(97.8)$ \\
\hline Redundancy & $3.7(3.5)$ & $3.0(3.2)$ \\
\hline \multicolumn{3}{|l|}{ Refinement statistics } \\
\hline Resolution $(\AA)$ & $42.4-2.50$ & $42.5-2.60$ \\
\hline No. of reflections & 52,627 & 47,912 \\
\hline$R_{\text {work }} / R_{\text {free }}$ & $0.2238 / 0.2569$ & $0.2161 / 0.2548$ \\
\hline \multicolumn{3}{|l|}{ No. of atoms } \\
\hline Protein & 11,615 & 11,615 \\
\hline Ligand/ion & 0 & 78 \\
\hline Water & 226 & 103 \\
\hline \multicolumn{3}{|l|}{$B$ factors } \\
\hline Protein & 71.08 & 76.44 \\
\hline Ligand/ion & & 123.80 \\
\hline Water & 61.82 & 87.08 \\
\hline \multicolumn{3}{|l|}{ RMSD } \\
\hline Bond length $(\AA)$ & 0.003 & 0.005 \\
\hline Bond angle $\left(^{\circ}\right)$ & 0.736 & 0.896 \\
\hline PDB code & $4 \mathrm{KPQ}$ & $4 \mathrm{KPS}$ \\
\hline
\end{tabular}

buffer. Glycan microarray printing and recombinant HA analyses have been described previously (27). The analyses were performed by application of the protein to the array at $200 \mu \mathrm{g} / \mathrm{ml}$ and detection in the second step with an anti-His antibody labeled with Alexa 488. Version 5.0 of the printed array consists of 611 glycans in replicates of six. The highest and lowest points from each set of six replicates were removed, so the average is of four values rather than six.

Crystallization, data collection, and structure determination. Crystallization conditions were screened using the hanging-drop vapor diffusion method with commercial kits (Hampton Research). H13 crystals were obtained with a reservoir solution $(0.2 \mathrm{ml})$ of $0.2 \mathrm{M} \mathrm{L}$-proline, $0.1 \mathrm{M}$ HEPES (pH 7.2), 10\% polyethylene glycol (PEG) 3350, and $0.01 \mathrm{M}$ sodium bromide at $20^{\circ} \mathrm{C}$. For receptor analog complexes, crystals were soaked in a reservoir solution containing $8 \mathrm{mM}$ LSTa or LSTc for $4 \mathrm{~h}$. $\mathrm{X}$-ray diffraction data were collected at $100 \mathrm{~K}$ at beamline NE3A of the Photon Factory, Tsukuba, Japan. X-ray diffraction data for the complex structure of H13 HA with LSTa (through crystal soaking) were collected at $100 \mathrm{~K}$ at Shanghai Synchrotron Radiation Facility (SSRF) beamline BL17U. These data were processed and scaled using the HKL-2000 program (39). Data collection and processing statistics are summarized in Table 1. The structures were solved by the molecular replacement (MR) method using Phaser (40) from the CCP4 program suite (41), with the structure of H16HA (Protein Data Bank [PDB] identifier 4 F23) as the search model. Model building and refinement were performed using the COOT (42) and REFMAC5 (43) programs, respectively. The stereochemical quality of the final models was assessed with the program PROCHECK (44).

Protein structure accession numbers. The crystal structures were deposited in the Protein Data Bank (PDB) under accession numbers 4KPQ and 4 KPS. 

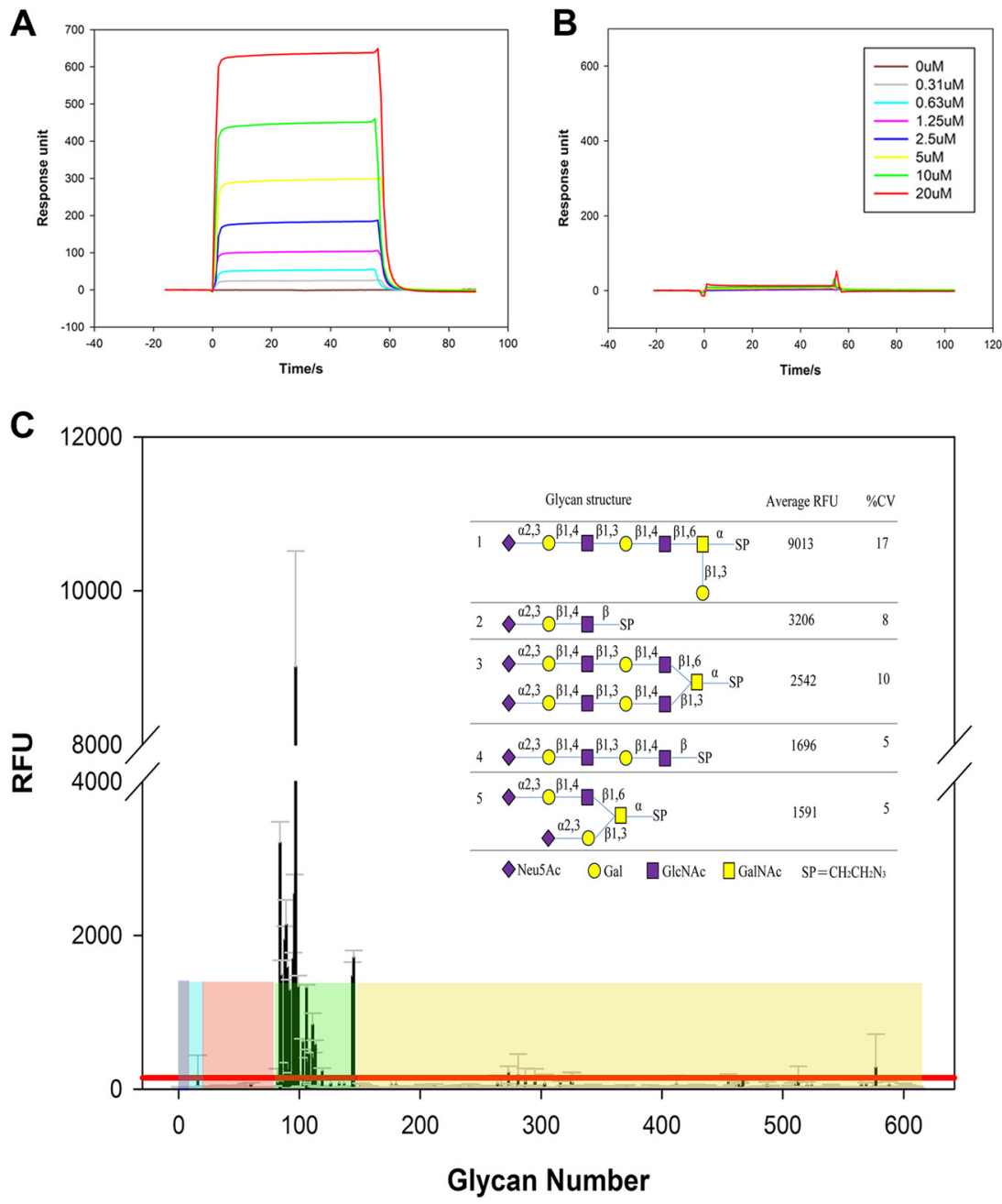

FIG 1 Receptor binding of the H13 protein. (A and B) SPR diagrams of H13 protein binding to the $\alpha 2$-3-linked and $\alpha 2-6$-linked sialic acid receptors. The H13 protein displayed exclusive binding to the $\alpha 2$-3-linked receptor. (C) Glycan microarray analysis of the H13 protein. Binding to different types of glycans on the array is highlighted, where blue represents Neu5Gc, cyan represents $\alpha 2,8$ ligands, magenta represents $\alpha 2-6$ ligands, green represents $\alpha 2-3$ ligands, and yellow represents other glycans. The H13 protein displayed a good avidity exclusively to $\alpha 2-3$ ligands. The structure formulas of the top representative are shown. Error bars represent the standard deviation of the mean value. Percent coefficient of variation $(\% \mathrm{CV})=100 \times$ standard deviation $/$ mean. A \%CV of less than $50 \%$ indicates data reliability.

\section{RESULTS}

Preferential avian $\alpha 2$-3-linked receptor binding activity. The sequence encoding the ectodomain of the H13 hemagglutinin from influenza A virus A/gull/Maryland/704/1977 (H13N6) was cloned into the pFastbacl vector and expressed using a baculovirus expression system as previously described (38). Next, SPR technology and glycan microarrays were used to investigate the receptor binding properties of the $\mathrm{H} 13$ protein. SPR experiments revealed that $\mathrm{H} 13$ binds exclusively to the canonical avian $\alpha 2-3$-linked receptor and not to the canonical human $\alpha 2-6$-linked receptor (Fig. $1 \mathrm{~A}$ and $\mathrm{B}$ ). The large-scale glycan microarray analysis with 611 different glycans, including natural sialosides ( $\alpha 2-3$-linkage, $\alpha 2$ 6 -linkage, $\alpha 2,8$-linkage, and mixed linkage) and other glycans that may be relevant to influenza virus biology, revealed that the $\mathrm{H} 13$ protein binds to only a few $\alpha 2$-3-linked glycans, with different relative fluorescence units (RFU) (Fig. 1C; see Table S1 in the supplemental material). The structural formulas of the top representative five glycans are shown in Fig. 1C. Although H13 shares a general preference for sialic acid with an $\alpha 2-3$ linkage to Gal-2, alternative linkages from GlcNAc- 3 to Gal-4 and subsequent glycan linkages could affect its binding activity.

Overall H13 structural features. The $\mathrm{H} 13$ structure was solved by molecular replacement (MR) at a resolution of $2.5 \AA$ using H16HA (PDB identifier 4F23) (19) as a search model (Table 1), and the sequence identity between $\mathrm{H} 13$ and $\mathrm{H} 16$ is $80.04 \%$. Although the $\mathrm{H} 13$ protein was expressed and purified in HA0 form, the solved H13 structure exhibits as a cleaved HA1/HA2 form. Only one molecule is observed in the asymmetrical unit. The crystal structure displays a classical homotrimer oligomerization as seen in other HA subtypes (Fig. 2). Seven asparagine-linked glycosylation sites are predicted in the H13 HA monomer, but interpretable carbohydrate electron density was observed at only one site, N169. Regarding this site, only one $N$-acetylglucosamine (GlcNAc) could be interpreted.

The phylogenetic tree in Fig. 2A shows that H13 indeed belongs to group $1 \mathrm{HAs}$, indicating that the $\mathrm{H} 13$ structure should resemble 

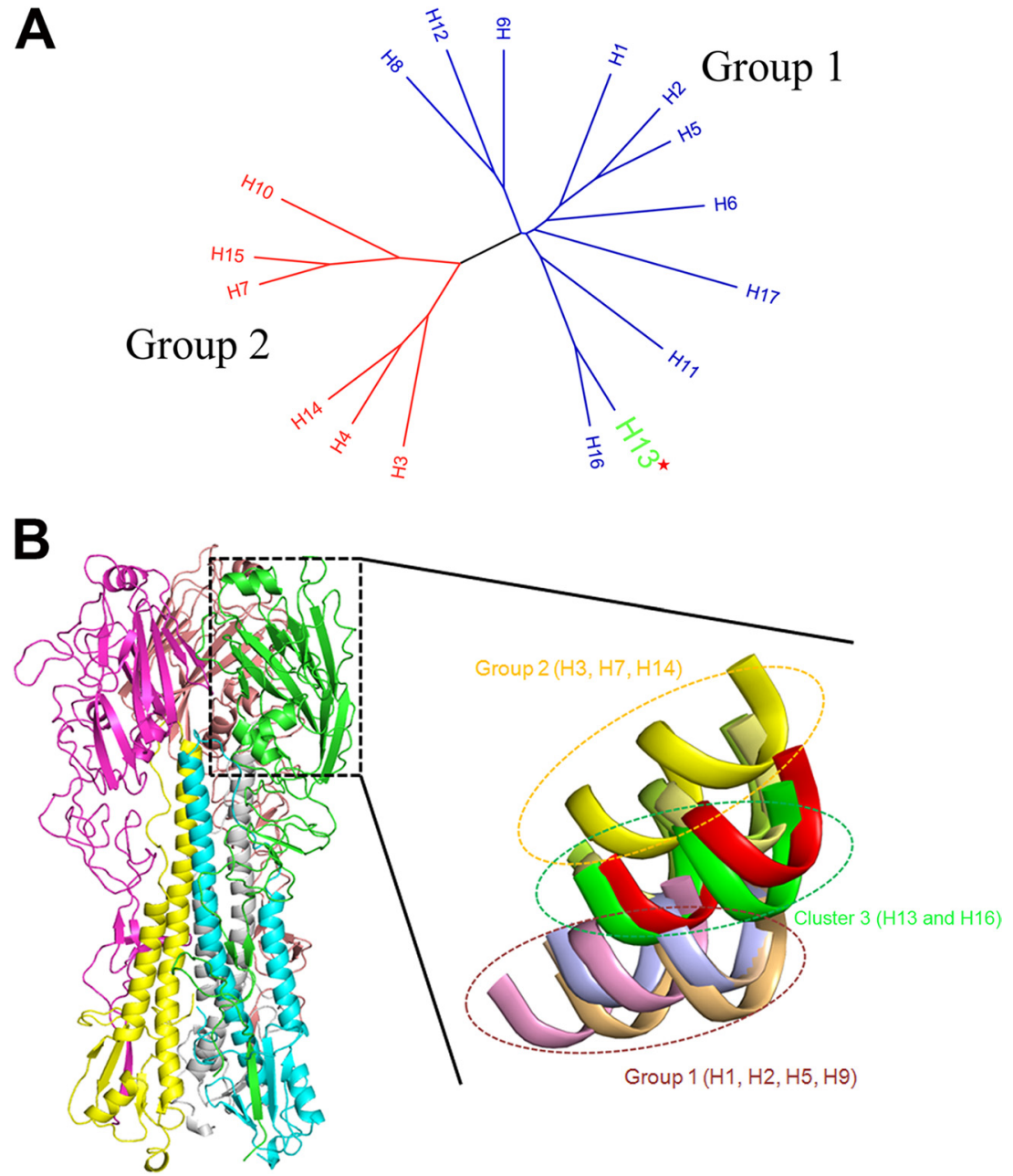

FIG 2 Phylogenetic tree and overall structure. (A) Phylogenetic tree showing that H13 belongs to group 1, in the same clade as H16. (B) Overall structure of H13 and comparison of the globular domain of the H13 monomer with those of other solved HA subtype structures (H1, light blue; H2, cyan; H3, limon; H5, light orange; H7, yellow; H9, pink; H14, pale yellow; H13, green; and H16, red). H13 displays a typical homotrimer structure. The 190 helix (residues 188 to 195 ) in the receptor binding domain was used as a representative of the globular subdomain of each HA subtype. The rigid-body orientation of the globular domain in the H13 structure is similar to that in the H16 subtype, by means of superimposition through the long helix of HA2. They are located between other group 1 HAs and group 2 HAs.

the structures of group 1 HAs rather than those of group 2. The superimposition of other HA structures onto the H13 monomer by means of their HA2 domains (root mean square deviations [RMSD] are given in Table 2) demonstrated that H13 is most closely related to the 1957 Singapore H2 subtype (RMSD = 0.634), whereas the avian H14 subtype is the most divergent $($ RMSD $=1.164)$. Based on their HA1 domains, H13 is most closely related to the avian $\mathrm{H} 16$ subtype $(\mathrm{RMSD}=0.480)$, whereas the 1968 Hong Kong H3 subtype is the most divergent $(\mathrm{RMSD}=$ 2.391). Concerning the receptor binding region ( $\mathrm{R}$ region) and vestigial esterase region (E region), $\mathrm{H} 13$ is still most closely related to the avian $\mathrm{H} 16$ subtype (RMSD $=0.454$ and 0.359 , respectively).

Previously solved HA structures demonstrate that there are group-specific features at sites where extensive conformational changes occur for HA activation, including the conformation of the interhelix loop and the rigid-body orientation of the globular domain. Here, we studied only whether the rule of the rigid-body orientation of the globular domain is applicable to recently solved H13 and H16 structures or not. Superimposition with other solved HA structures by means of the long central $\alpha$-helices of HA2 revealed that the rigid-body orientations of globular domains fall into three clusters: group 1, including $\mathrm{H} 1, \mathrm{H} 2, \mathrm{H}$, and H9; group 2, including H3, H7, and H14; and "cluster 3," consisting of $\mathrm{H} 16$ and $\mathrm{H} 13$. Cluster 3 (H13 and H16) is located between the group 1 HAs and group 2 HAs. These differences may result in different mechanisms of HA activation, which should be the subject of a future study.

Structural basis for receptor binding specificity. The crystals of $\mathrm{H} 13$ were soaked with the pentasaccharides LSTc and LSTa, which represent $\alpha 2-6$ - and $\alpha 2$-3-linked glycan analogs of human and avian receptors, respectively. However, only LSTa successfully soaked into the crystal to form a complex, which is consistent with the SPR experiments (i.e., only LSTa binds H13). The structural formula of LSTa is NeuAc $\alpha 2-3 \mathrm{Gal} \beta 1-3 \mathrm{GlcNAc} \beta 1-3 \mathrm{Gal} \beta 1-4 \mathrm{Glc}$. In the H13/LSTa complex structure, strong electron density for the glycan ligand is observed in the receptor binding sites of two of the three monomers in the asymmetric unit. It is possible that the crystal packing limits the glycan receptor analog binding in the 
TABLE 2 Comparison of RMSD for individual domains ${ }^{a}$

\begin{tabular}{|c|c|c|c|c|c|c|}
\hline \multirow[b]{2}{*}{ Group } & \multirow[b]{2}{*}{ Subtype } & \multirow[b]{2}{*}{$\begin{array}{l}\text { PDB } \\
\text { entry }\end{array}$} & \multicolumn{4}{|c|}{ RMSD $(\AA)$ for: } \\
\hline & & & $\begin{array}{l}\text { HA2 } \\
\text { domain }\end{array}$ & $\begin{array}{l}\text { HAl } \\
\text { domain }\end{array}$ & $\begin{array}{l}\text { HA1 R } \\
\text { region }\end{array}$ & $\begin{array}{l}\mathrm{HA} 1 \mathrm{E} \\
\text { region }\end{array}$ \\
\hline \multirow[t]{7}{*}{1} & $\mathrm{Hu}-\mathrm{H} 1$ & 1RD8 & 1.002 & 2.176 & 0.940 & 2.130 \\
\hline & $\mathrm{Hu}-\mathrm{H} 1$ & $3 \mathrm{AL} 4$ & 0.861 & 1.953 & 0.909 & 1.483 \\
\hline & $\mathrm{Hu}-\mathrm{H} 2$ & $2 \mathrm{WRC}$ & 0.634 & 1.913 & 0.800 & 0.834 \\
\hline & $\mathrm{Hu}-\mathrm{H} 5$ & $2 \mathrm{FK} 0$ & 0.843 & 2.291 & 1.177 & 1.216 \\
\hline & $\mathrm{Av}-\mathrm{H} 5$ & $1 \mathrm{JSM}$ & 0.908 & 1.829 & 0.857 & 1.238 \\
\hline & Sw-H9 & 1JSD & 1.042 & 1.583 & 0.912 & 2.537 \\
\hline & Av-H16 & $4 \mathrm{~F} 23$ & 1.014 & 0.480 & 0.454 & 0.359 \\
\hline \multirow[t]{3}{*}{2} & $\mathrm{Hu}-\mathrm{H} 3$ & $2 \mathrm{HMG}$ & 1.103 & 2.391 & 1.008 & 4.330 \\
\hline & Tu-H7 & $1 \mathrm{TI} 8$ & 1.061 & 2.366 & 1.109 & 3.050 \\
\hline & $\mathrm{Av}-\mathrm{H} 14$ & $3 \mathrm{EYJ}$ & 1.164 & 1.950 & 1.064 & 1.753 \\
\hline
\end{tabular}

${ }^{a}$ Each domain was superimposed separately to determine how the individual $\mathrm{H} 13 \mathrm{HA}$ domains compared to equivalent domains in the other structures. $\mathrm{R}$ region, receptor binding domain region; E region, vestigial esterase region. PDB accession numbers for genes/proteins used in this work: A/South Carolina/1/18 (H1N1), 1RD8; A/California/ 04/2009 (H1N1), 3AL4; A/Singapore/1/1957 (H2N2), 2WRC; A/Viet Nam/1203/04 (H5N1), 2FK0; A/Duck/Singapore/3/97 (H5N3), 1JSM; A/Swine/Hong Kong/9/98 (H9N2), 1JSD; A/Black-Headed Gull/Sweden/2/99 (H16N3), 4F23; A/Hong Kong/1/68 (H3N2), 2HMG; A/Turkey/Italy/8000/02 (H7N3), 1TI8; A/mallard/Astrakhan/263/ 1982 (H14N5), 3EYJ.

third monomer or that the soaking time with the receptor analogs was not long enough to get full occupancy. In one site, only Sia-1 and Gal-2 are observed, and in the other site, Sia-1, Gal-2, and GlcNAc-3 are observed. To our surprise, the protein-ligand hydrogen bond interactions converge on Sia-1 (Table 3 and Fig. 3A), with no binding to other sugars (including Gal-2 and GlcNAc-3). Nine hydrogen bonds are formed between Sia-1 and residues (Y98, T135, T136, S137, Q226, and S228) within the receptor binding pocket (Table 3 and Fig. 3A). Notably, Q226 and S228, two key residues for receptor binding specificity and host adaptation, form most (five) of the hydrogen bonds.

Previous studies have revealed that Q226L and G228S substitutions can shift the receptor binding specificity from the $\alpha 2-3-$ linked avian receptor to the $\alpha-2-6$-linked human receptor in $\mathrm{H} 2$, H3, and H5 (9). Furthermore, the G228S single substitution increases human receptor binding affinity in H5 (24). However, in $\mathrm{H} 13$, residue 228 is naturally an S, and the H13 protein still binds exclusively to the $\alpha 2$-3-linked avian receptor. Thus, we compared these two complex structures (H13/LSTa and H5/LSTa) (45) and found that the hydrogen bond interactions are different. First, in the H5/LSTa complex structure, the G228 residue forms a hydrogen bond with Sia-1 mediated by a water molecule; in the H13/ LSTa complex structure, S228 directly forms a hydrogen bond with Sia-1 (Fig. 3A and B). Second, in the H5/LSTa complex structure, residue E190 forms a hydrogen bond with Sia-1, but in the H13/LSTa complex structure, E190 does not form any hydrogen bond with Sia-1 (Fig. 3A and B). This difference might result from the different residues at position 186. In the H5/LSTa complex structure, N186 forms a hydrogen bond with E190 and stabilizes the side chain of E190 to point toward the Sia-1 (Fig. 3C). However, in the H13/LSTa complex structure, V186 creates a hydrophobic environment and might make the side chain of E190 fold back toward the 190 helix (Fig. 3C). Analysis of the virus isolates in the NCBI Flu database reveals that the residue N186 is highly conserved in the $\mathrm{H} 5$ subtype $(2,932 / 2,948$ isolates have $\mathrm{N})$ and the
TABLE 3 Hydrogen bond interactions between H13 and LSTa

\begin{tabular}{lll}
\hline $\mathrm{H}_{13} \mathrm{HA} / \mathrm{LSTa}^{a}$ & Protein, residue & Avg bond distance $(\AA)$ \\
\hline O1A & OG, S137 & 3.41 \\
& NE2, Q226 & 3.43 \\
O1B & OE1, Q226 & 2.73 \\
& OG1, T136 & 2.79 \\
& NE2, Q226 & 2.75 \\
N5 & O, T135 & 3.38 \\
O8 & OE1, Q226 & 2.47 \\
O8 & OH, Y98 & 2.55 \\
O9 & OG, S228 & 3.31 \\
\hline
\end{tabular}

${ }^{a}$ All protein-ligand hydrogen bond interactions converged on Sia-1.

residue V186 is highly conserved in the H13 subtype (56/57 isolates have $\mathrm{V}$ ).

In order to confirm the importance of residue V186 in the receptor binding of $\mathrm{H} 13$ protein, we generated the $\mathrm{H} 13 \mathrm{~N} 186 \mathrm{mu}-$ tant protein and measured receptor binding using the SPR method. We found that this mutant protein reduced the binding of the avian receptor analog, but increased the binding of the human receptor analog, compared with wild-type H13 protein (Fig. 4).

Superimposing the receptor binding pockets, the Sia-1 is dragged more toward the 220 loop in H13. This structural feature allows Q226 to form more hydrogen bonds with Sia-1 in H13. It is well established that avian and human HAs distinguish avian and human receptors by atomic contacts at the glycosidic linkage between Sia-1 and Gal-2. The $\alpha 2$-3-linked avian receptor binds avian HA in a trans conformation to form an $\alpha 2$-3 linkage-specific motif, made by the glycosidic oxygen and $4-\mathrm{OH}$ of Gal-2, that is complementary to the hydrogen bonding capacity of Q226, an avian-specific residue. The $\alpha 2-6$-linked human receptor binds human HA in a cis conformation, exposing the glycosidic oxygen to solution and nonpolar atoms of the receptor to L226, a humanspecific residue. According to these binding rules, if the $\alpha 2-6-$ linked human receptor bound H13, the closer distance would drive the nonpolar atoms of the human receptor into a stronger clash with the hydrophilic residue Q226 (which is in the 220 loop). Therefore, combined with the lack of hydrogen bond interactions mediated by E190, this might explain why the $\mathrm{H} 13$ protein binds exclusively to the $\alpha-2-3$-linked avian receptor.

Conserved binding sites for the broadly neutralizing antiHA2 antibodies. The HA of influenza virus is the major target for vaccine design (46). Recently, several cross-reactive anti-HA2 antibodies have been found to neutralize a wide spectrum of influenza A viruses by binding to highly conserved epitopes in the stem region of HA (47-50). Among these antibodies, FI6 binds all HA subtypes (H1 to H16) (48). The crystal structure of the FI6-09H1 complex reveals that the antibody targets a shallow hydrophobic groove on the F subdomain of $\mathrm{HA}$, where the sides of the groove are formed by the residues from the A helix of HA2 (including L38, T41, I45, and I48) and parts of two strands of HA1 (including V40 and T318), as well as the HA2 turn (including W21) encompassing residues 18 to 21 (Fig. 5A). In $\mathrm{H} 13 \mathrm{HA}$, a similar hydrophobic groove is observed, but it contains two different residues, I40 and K38 (Fig. 5B). Thus, we deduced that the FI6 cross-reactive anti-HA2 neutralizing antibody can bind to the $\mathrm{H} 13$ protein (Fig. 5). 

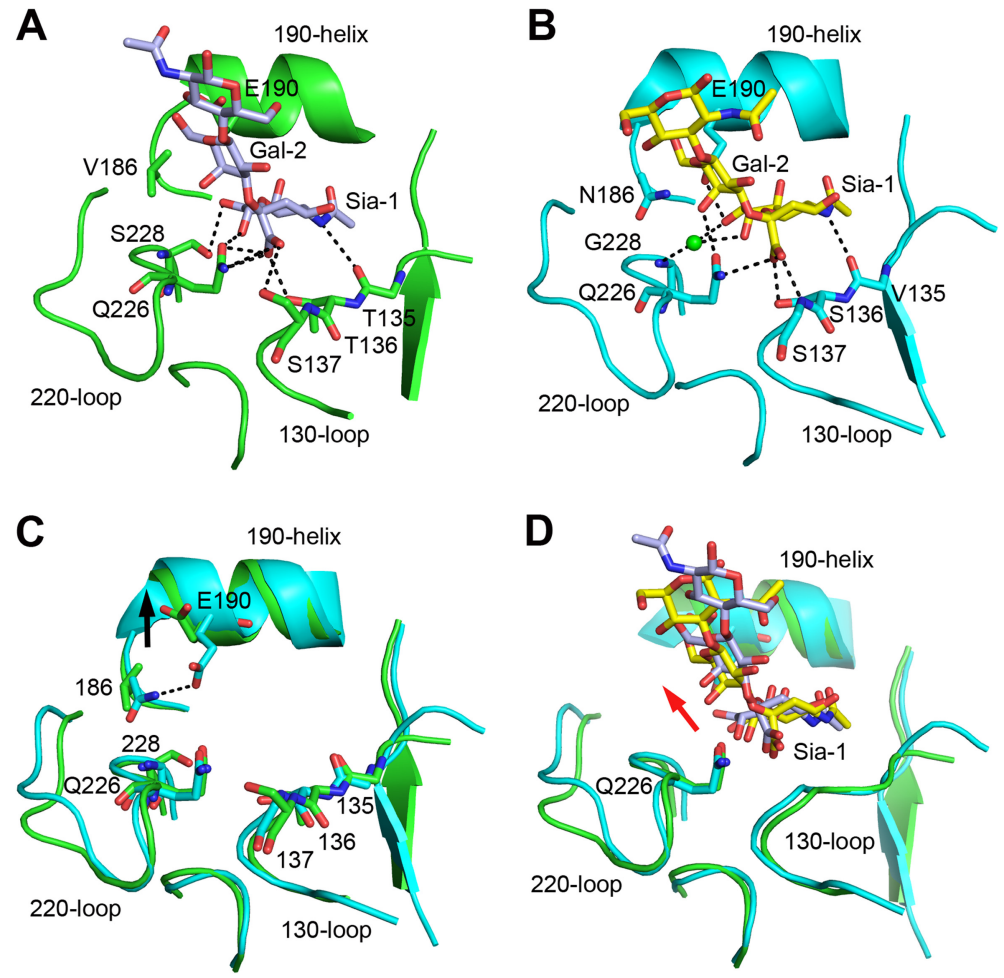

FIG 3 Interaction of H13 protein with an avian receptor analog and comparison with the H5/avian receptor analog complex. The three secondary structure elements of the binding site (the 130 loop, 190 helix, and 220 loop) are labeled in ribbon representation together with selected residues in stick representation. Hydrogen bonds are shown as dashed lines. (A) H13 protein with the avian receptor analog LSTa ( $\alpha 2-3)$ pentasaccharide bound, colored in green. The interaction with the receptor binding site converges on Sia-1. (B) H5 protein with the avian receptor analog LSTa pentasaccharide bound (PDB accession number 1JSN), colored in cyan. Both Sia-1 and Gal-2 are involved in the interaction with the receptor binding site. (C and D) Comparison of the receptor binding sites of the H13/LSTa and H5/LSTa complexes. The hydrophobic residue V186 creates a hydrophobic environment to force the side chain of E190 to adopt a fold-back conformation in H13. The equivalent residue N186 stabilizes the side chain of E190 to point to the receptor binding site in H5. The glycan ligand is closer to the 220 loop in the H13/LSTa complex than in the H5/LSTa complex.

\section{DISCUSSION}

An increasing number of cases of human infections by the H5N1 highly pathogenic avian influenza virus (HPAIV) underscores the real public health concern about potential pandemics or endemics caused by influenza viruses with an avian origin (51). Recent work $(33,34)$ on $\mathrm{H} 5 \mathrm{~N} 1$ virus adaptation to horizontal transmission in ferrets has again alerted the public and the scientific community to the possibility of human infection by avian-origin influenza virus. Studies on the virulence evolution and/or interspecies transmission of avian viruses cannot be suspended under such circumstances. The H13 subtype was originally isolated from seagulls in 1977 (36) and causes illness in ferrets upon direct inoculation (36). Thus, detailed studies of $\mathrm{H} 13$ receptor binding and structure are highly relevant to avian-to-mammalian transmission of lowpathogenic avian influenza virus (LPAIV).

In this study, we solved the H13 crystal structure and characterized its receptor binding, revealing that $\mathrm{H} 13$ has a typical HA structure and is cleaved into HA1 and HA2 in the crystal structure. Our results demonstrated that the avian $\mathrm{H} 13$ displays exclusive binding to the avian receptor (i.e., the $\alpha 2-3$ linked sialic acid receptor), whereas other avian HAs (e.g., H1, $\mathrm{H} 2, \mathrm{H} 3$, and $\mathrm{H} 5$ ) both bind the avian receptor and possess weak binding affinity for the human receptor (i.e., the $\alpha 2$-6-linked sialic acid receptor). Notably, the H13 HA bound well to linearsequence fragments (structures 2 and 4 in Fig. 1C) and the same sequences on selected O-linked glycans but bound with reduced avidity to glycans containing the same terminal sequences attached to $\mathrm{N}$-linked glycan cores, consistent with previous analysis on a more limited set of glycans (52). Structural analysis revealed that $\mathrm{H} 13$ has a typical $\alpha 2-3$-linked sialic acid receptor binding groove, as confirmed by a receptor-H13 complex structure. The hydrogen bond interactions between the sialyl glycan receptor and the receptor binding site of $\mathrm{H} 13$ converge on the sialic acid (Sia-1), with no binding to the glycans. Furthermore, the residue E190 does not form hydrogen bonds with Sia-1 in the H13/LSTa complex structure. This lack of hydrogen bond interactions results from the fold-back conformation of E190, which might be generated by the nearby hydrophobic residue V186. However, in other avian HAs (H5 and $\mathrm{H} 2$ subtypes), the residue at position 186 is usually an asparagine (N) (308/308 virus isolates of $\mathrm{H} 2$ in the NCBI Flu database have N). Previous studies show that the residues E190 and N186 contribute to the binding of the human receptor via a water-mediated hydrogen bond network in other HA subtypes (26). Thus, the hydrophobic residue V186 precludes the binding of $\mathrm{H} 13$ to the human receptor, which is also confirmed by our work with the H13N186 mutant. In terms of interspecies transmission, a Q226L substitution in the receptor binding site might help H13 to obtain human $\alpha 2-6$-linked sialic acid receptor binding, as the same Q226L substitution helps H5 to obtain 
A

H13 to $\alpha 2-3$ glycan

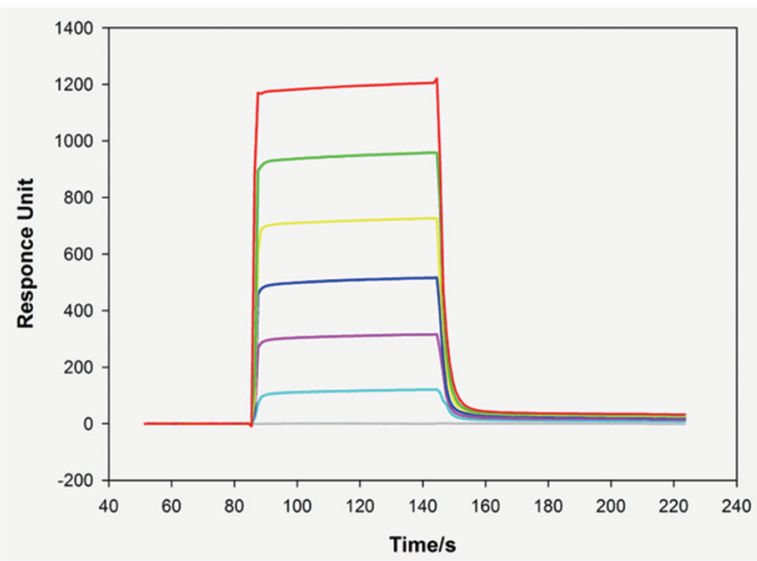

$\mathrm{C}$

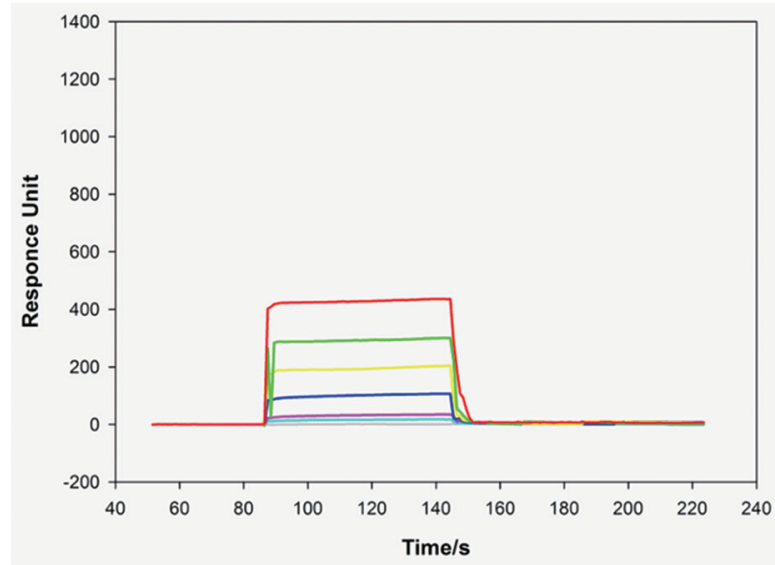

$\mathrm{B}$

H13 to $\alpha 2-6$ glycan

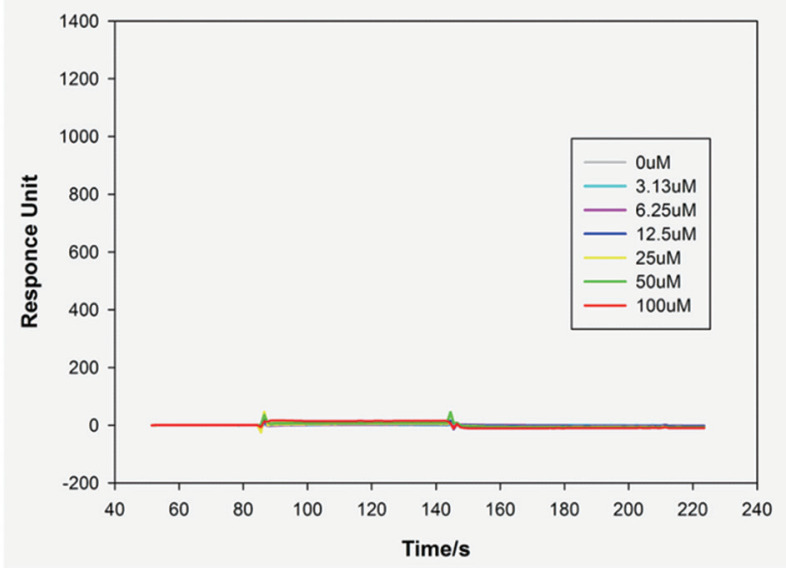

D

H13N186 to $\alpha 2-6$ glycan

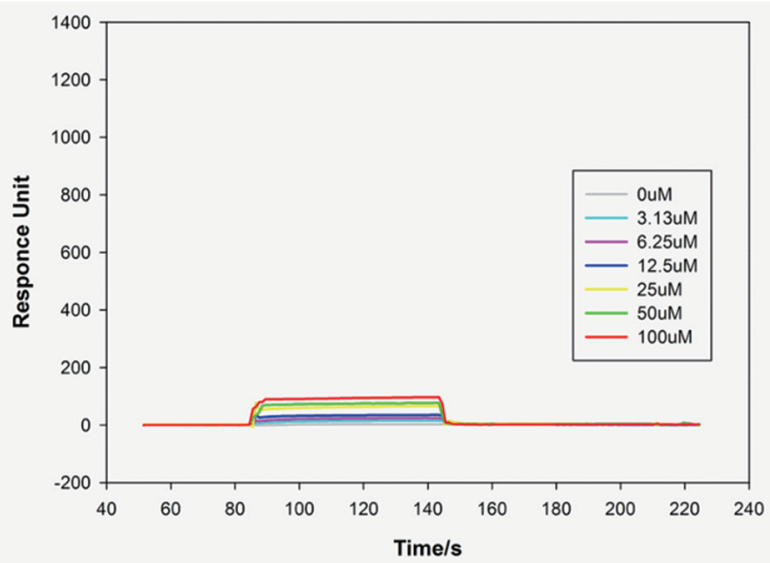

FIG 4 Receptor binding of the H13N186 mutant protein. (A and B) SPR diagrams of H13 protein binding to the $\alpha 2-3$-linked and $\alpha 2-6$-linked sialic acid receptors with a series of higher concentrations. The H13 protein still displayed exclusive binding to the $\alpha 2-3$-linked receptor. (C and D) SPR diagrams of H13N186 protein binding to the $\alpha 2-3$-linked and $\alpha 2$-6-linked sialic acid receptors. The H13N186 protein reduced the binding to the $\alpha 2-3$-linked receptor but increased the binding to $\alpha 2-6$-linked receptor.
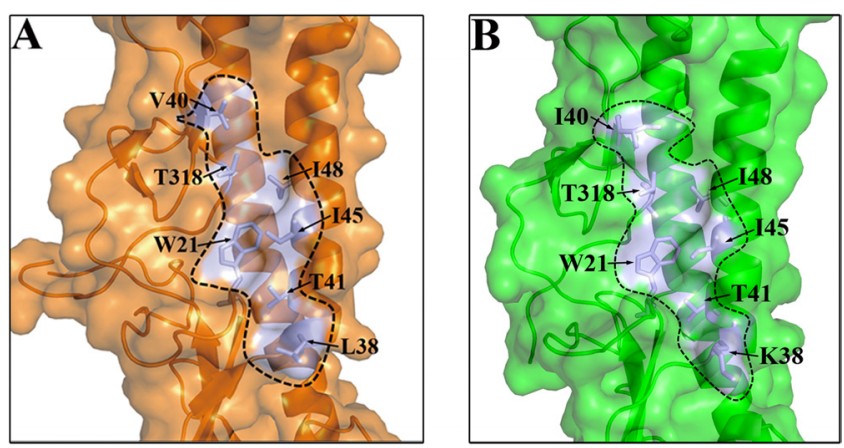

FIG 5 The conserved hydrophobic groove in the H13 protein reveals the structural basis of binding by the broadly neutralizing antibody FI6. Surface representations of the F subdomains of 09H1 HA (A) and H13 HA (B) with selected side chains that contribute to the conserved hydrophobic groove are shown. The approximate boundaries of the hydrophobic grooves are indicated by the black lines. Although the residues contributing to the hydrophobic groove are moderately different between $09 \mathrm{H} 1$ and $\mathrm{H} 13$, similar hydrophobic grooves guarantee the binding potential by the FI6 antibody. human receptor binding (34). Therefore, evidence of this mutation should be closely monitored in the future for influenza virus surveillance.

Detailed analysis of the HA structure also revealed that the binding sites of the recently well-studied HA2-targeting neutralizing monoclonal antibodies are highly conserved. Therefore, these human monoclonal antibodies should neutralize viruses encoding H13, but they need to be (minimally) tested in an animal model. Future work should also focus on the structures and receptor binding activities of other LPAIV HAs.

\section{ACKNOWLEDGMENTS}

This work was supported by grants from the Ministry of Science and Technology of China (project 973, grant no. 2011CB504703; http://www .most.gov.cn/eng/). We acknowledge the Consortium for Functional Glycomics for glycan array analysis and synthetic glycans used in binding assays (NIH grant GM62116). G.F.G. is a leading principal investigator of the Innovative Research Group of the National Natural Science Foundation of China (grant no. 81021003; http://www.nsfc.gov.cn/Portal0 /default106.htm). 
The funders had no role in study design, data collection and analysis, decision to publish, or preparation of the manuscript.

We thank the staff at the Shanghai Synchrotron Radiation Facility and the staff at the Photon Factory (Tsukuba, Japan) for assistance.

G.F.G. supervised and oversaw the project; G.F.G., X.L., and Y.S. conceived the research; X.L. performed the protein expression, purification, and crystallization; Y.Z. prepared the insect cells; J.Q. performed the structure determination; D.F.S., and J.H.-M. performed the glycan array experiments; J.C.P. provided advice about receptor binding experiments; G.F.G., Y.S., X.L., H.X., and M.W. performed the data analysis; Y.S., X.L., and G.F.G. wrote the manuscript; all authors reviewed and edited the manuscript.

We declare that we have no conflict of interest.

\section{REFERENCES}

1. Frank AL, Taber LH, Glezen WP, Geyer EA, McIlwain S, Paredes A. 1983. Influenza B virus infections in the community and the family. The epidemics of 1976-1977 and 1979-1980 in Houston, Texas. Am. J. Epidemiol. 118:313-325.

2. Gao GF, Sun Y. 2010. It is not just AIV: from avian to swine-origin influenza virus. Sci. China Life Sci. 53:151-153.

3. Guan Y, Vijaykrishna D, Bahl J, Zhu H, Wang J, Smith GJ. 2010. The emergence of pandemic influenza viruses. Protein Cell 1:9-13.

4. Neumann G, Noda T, Kawaoka Y. 2009. Emergence and pandemic potential of swine-origin H1N1 influenza virus. Nature 459:931-939.

5. Webster RG, Bean WJ, Gorman OT, Chambers TM, Kawaoka Y. 1992. Evolution and ecology of influenza A viruses. Microbiol. Rev. 56:152-179.

6. WHO. 1980. A revision of the system of nomenclature for influenza viruses: a WHO memorandum. Bull. World Health Organ. 58:585-591.

7. Air GM. 1981. Sequence relationships among the hemagglutinin genes of 12 subtypes of influenza A virus. Proc. Natl. Acad. Sci. U. S. A. 78:76397643.

8. Nobusawa E, Aoyama T, Kato H, Suzuki Y, Tateno Y, Nakajima K. 1991. Comparison of complete amino acid sequences and receptorbinding properties among 13 serotypes of hemagglutinins of influenza A viruses. Virology 182:475-485.

9. Gamblin SJ, Skehel JJ. 2010. Influenza hemagglutinin and neuraminidase membrane glycoproteins. J. Biol. Chem. 285:28403-28409.

10. Tong S, Li Y, Rivailler P, Conrardy C, Castillo DA, Chen LM, Recuenco S, Ellison JA, Davis CT, York IA, Turmelle AS, Moran D, Rogers S, Shi M, Tao Y, Weil MR, Tang K, Rowe LA, Sammons S, Xu X, Frace M, Lindblade KA, Cox NJ, Anderson LJ, Rupprecht CE, Donis RO. 2012. A distinct lineage of influenza A virus from bats. Proc. Natl. Acad. Sci. U. S. A. 109:4269-4274.

11. Russell RJ, Haire LF, Stevens DJ, Collins PJ, Lin YP, Blackburn GM, Hay AJ, Gamblin SJ, Skehel JJ. 2006. The structure of H5N1 avian influenza neuraminidase suggests new opportunities for drug design. Nature 443:45-49.

12. Rogers GN, Pritchett TJ, Lane JL, Paulson JC. 1983. Differential sensitivity of human, avian, and equine influenza A viruses to a glycoprotein inhibitor of infection: selection of receptor specific variants. Virology 131: $394-408$.

13. Webster RG, Yakhno M, Hinshaw VS, Bean WJ, Murti KG. 1978. Intestinal influenza: replication and characterization of influenza viruses in ducks. Virology 84:268-278.

14. Naeve CW, Hinshaw VS, Webster RG. 1984. Mutations in the hemagglutinin receptor-binding site can change the biological properties of an influenza virus. J. Virol. 51:567-569.

15. Baum LG, Paulson JC. 1990. Sialyloligosaccharides of the respiratory epithelium in the selection of human influenza virus receptor specificity. Acta Histochem. Suppl. 40:35-38.

16. Couceiro JN, Paulson JC, Baum LG. 1993. Influenza virus strains selectively recognize sialyloligosaccharides on human respiratory epithelium; the role of the host cell in selection of hemagglutinin receptor specificity. Virus Res. 29:155-165.

17. Matrosovich MN, Matrosovich TY, Gray T, Roberts NA, Klenk HD. 2004. Human and avian influenza viruses target different cell types in cultures of human airway epithelium. Proc. Natl. Acad. Sci. U. S. A. 101: 4620-4624.

18. Medina RA, Garcia-Sastre A. 2011. Influenza A viruses: new research developments. Nat. Rev. Microbiol. 9:590-603.
19. Lu X, Shi Y, Gao F, Xiao H, Wang M, Qi J, Gao GF. 2012. Insights into avian influenza virus pathogenicity: the hemagglutinin precursor HA0 of subtype H16 has an alpha-helix structure in its cleavage site with inefficient HA1/HA2 cleavage. J. Virol. 86:12861-12870.

20. Wilson IA, Skehel JJ, Wiley DC. 1981. Structure of the haemagglutinin membrane glycoprotein of influenza virus at 3 A resolution. Nature 289: 366-373.

21. Ha Y, Stevens DJ, Skehel JJ, Wiley DC. 2002. H5 avian and H9 swine influenza virus haemagglutinin structures: possible origin of influenza subtypes. EMBO J. 21:865-875.

22. Russell RJ, Gamblin SJ, Haire LF, Stevens DJ, Xiao B, Ha Y, Skehel JJ. 2004. H1 and H7 influenza haemagglutinin structures extend a structural classification of haemagglutinin subtypes. Virology 325:287-296.

23. Stevens J, Corper AL, Basler CF, Taubenberger JK, Palese P, Wilson IA. 2004. Structure of the uncleaved human H1 hemagglutinin from the extinct 1918 influenza virus. Science 303:1866-1870.

24. Stevens J, Blixt O, Tumpey TM, Taubenberger JK, Paulson JC, Wilson IA. 2006. Structure and receptor specificity of the hemagglutinin from an H5N1 influenza virus. Science 312:404-410.

25. Russell RJ, Kerry PS, Stevens DJ, Steinhauer DA, Martin SR, Gamblin SJ, Skehel JJ. 2008. Structure of influenza hemagglutinin in complex with an inhibitor of membrane fusion. Proc. Natl. Acad. Sci. U. S. A. 105: 17736-17741.

26. Liu J, Stevens DJ, Haire LF, Walker PA, Coombs PJ, Russell RJ, Gamblin SJ, Skehel JJ. 2009. Structures of receptor complexes formed by hemagglutinins from the Asian influenza pandemic of 1957. Proc. Natl. Acad. Sci. U. S. A. 106:17175-17180.

27. Sun X, Shi Y, Lu X, He J, Gao F, Yan J, Qi J, Gao GF. 2013. Bat-derived influenza hemagglutinin h17 does not bind canonical avian or human receptors and most likely uses a unique entry mechanism. Cell Rep. 3:769-778.

28. Zhu X, Yu W, McBride R, Li Y, Chen LM, Donis RO, Tong S, Paulson JC, Wilson IA. 2013. Hemagglutinin homologue from H17N10 bat influenza virus exhibits divergent receptor-binding and $\mathrm{pH}$-dependent fusion activities. Proc. Natl. Acad. Sci. U. S. A. 110:1458-1463.

29. Brown IH. 2010. Summary of avian influenza activity in Europe, Asia, and Africa, 2006-2009. Avian Dis. 54:187-193.

30. de Jong JC, Rimmelzwaan GF, Bartelds AI, Wilbrink B, Fouchier RA, Osterhaus AD. 2003. The 2002/2003 influenza season in the Netherlands and the vaccine composition for the 2003/2004 season. Ned. Tijdschr. Geneeskd. 147:1971-1975.

31. Peiris M, Yuen KY, Leung CW, Chan KH, Ip PL, Lai RW, Orr WK, Shortridge KF. 1999. Human infection with influenza H9N2. Lancet 354: 916-917.

32. Subbarao K, Klimov A, Katz J, Regnery H, Lim W, Hall H, Perdue M, Swayne D, Bender C, Huang J, Hemphill M, Rowe T, Shaw M, Xu X, Fukuda K, Cox N. 1998. Characterization of an avian influenza A (H5N1) virus isolated from a child with a fatal respiratory illness. Science 279:393396.

33. Herfst S, Schrauwen EJ, Linster M, Chutinimitkul S, de Wit E, Munster VJ, Sorrell EM, Bestebroer TM, Burke DF, Smith DJ, Rimmelzwaan GF, Osterhaus AD, Fouchier RA. 2012. Airborne transmission of influenza A/H5N1 virus between ferrets. Science 336:1534-1541.

34. Imai M, Watanabe T, Hatta M, Das SC, Ozawa M, Shinya K, Zhong G, Hanson A, Katsura H, Watanabe S, Li C, Kawakami E, Yamada S, Kiso M, Suzuki Y, Maher EA, Neumann G, Kawaoka Y. 2012. Experimental adaptation of an influenza H5 HA confers respiratory droplet transmission to a reassortant H5 HA/H1N1 virus in ferrets. Nature 486:420-428.

35. Velarde R, Calvin SE, Ojkic D, Barker IK, Nagy E. 2010. Avian influenza virus $\mathrm{H} 13$ circulating in ring-billed gulls (Larus delawarensis) in southern Ontario, Canada. Avian Dis. 54:411-419.

36. Hinshaw VS, Air GM, Gibbs AJ, Graves L, Prescott B, Karunakaran D. 1982. Antigenic and genetic characterization of a novel hemagglutinin subtype of influenza A viruses from gulls. J. Virol. 42:865-872.

37. Hofle U, Van de Bildt MW, Leijten LM, Van Amerongen G, Verhagen JH, Fouchier RA, Osterhaus AD, Kuiken T. 2012. Tissue tropism and pathology of natural influenza virus infection in black-headed gulls (Chroicocephalus ridibundus). Avian Pathol. 41:547-553.

38. Zhang W, Qi J, Shi Y, Li Q, Gao F, Sun Y, Lu X, Lu Q, Vavricka CJ, Liu D, Yan J, Gao GF. 2010. Crystal structure of the swine-origin A (H1N1)2009 influenza A virus hemagglutinin (HA) reveals similar antigenicity to that of the 1918 pandemic virus. Protein Cell 1:459-467.

39. Vaguine AA, Richelle J, Wodak SJ. 1999. SFCHECK: a unified set of 
procedures for evaluating the quality of macromolecular structure-factor data and their agreement with the atomic model. Acta Crystallogr. D Biol. Crystallogr. 55:191-205.

40. Read RJ. 2001. Pushing the boundaries of molecular replacement with maximum likelihood. Acta Crystallogr. D Biol. Crystallogr. 57:1373-1382.

41. Collaborative Computational Project. 1994. The CCP4 suite: programs for protein crystallography. Acta Crystallogr. D Biol. Crystallogr. 50:760 763.

42. Emsley P, Cowtan K. 2004. Coot: model-building tools for molecular graphics. Acta Crystallogr. D Biol. Crystallogr. 60:2126-2132.

43. Murshudov GN, Vagin AA, Dodson EJ. 1997. Refinement of macromolecular structures by the maximum-likelihood method. Acta Crystallogr. D Biol. Crystallogr. 53:240-255.

44. Morris AL, MacArthur MW, Hutchinson EG, Thornton JM. 1992. Stereochemical quality of protein structure coordinates. Proteins 12:345364.

45. Ha Y, Stevens DJ, Skehel JJ, Wiley DC. 2001. X-ray structures of H5 avian and $\mathrm{H} 9$ swine influenza virus hemagglutinins bound to avian and human receptor analogs. Proc. Natl. Acad. Sci. U. S. A. 98:11181-11186.

46. Xuan C, Shi Y, Qi J, Zhang W, Xiao H, Gao GF. 2011. Structural vaccinology: structure-based design of influenza A virus hemagglutinin subtype-specific subunit vaccines. Protein Cell 2:997-1005.

47. Ekiert DC, Friesen RH, Bhabha G, Kwaks T, Jongeneelen M, Yu W, Ophorst C, Cox F, Korse HJ, Brandenburg B, Vogels R, Brakenhoff JP, Kompier R, Koldijk MH, Cornelissen LA, Poon LL, Peiris M, Koudstaal
W, Wilson IA, Goudsmit J. 2011. A highly conserved neutralizing epitope on group 2 influenza A viruses. Science 333:843-850.

48. Corti D, Voss J, Gamblin SJ, Codoni G, Macagno A, Jarrossay D, Vachieri SG, Pinna D, Minola A, Vanzetta F, Silacci C, FernandezRodriguez BM, Agatic G, Bianchi S, Giacchetto-Sasselli I, Calder L, Sallusto F, Collins P, Haire LF, Temperton N, Langedijk JP, Skehel JJ, Lanzavecchia A. 2011. A neutralizing antibody selected from plasma cells that binds to group 1 and group 2 influenza A hemagglutinins. Science 333:850-856.

49. Ekiert DC, Bhabha G, Elsliger MA, Friesen RH, Jongeneelen M, Throsby M, Goudsmit J, Wilson IA. 2009. Antibody recognition of a highly conserved influenza virus epitope. Science 324:246-251.

50. Sui J, Hwang WC, Perez S, Wei G, Aird D, Chen LM, Santelli E, Stec B, Cadwell G, Ali M, Wan H, Murakami A, Yammanuru A, Han T, Cox NJ, Bankston LA, Donis RO, Liddington RC, Marasco WA. 2009. Structural and functional bases for broad-spectrum neutralization of avian and human influenza A viruses. Nat. Struct. Mol. Biol. 16:265-273.

51. Neumann G, Macken CA, Karasin AI, Fouchier RA, Kawaoka Y. 2012 Egyptian H5N1 influenza viruses-cause for concern? PLoS Pathog. 8:e1002932. doi:10.1371/journal.ppat.1002932.

52. Nycholat CM, McBride R, Ekiert DC, Xu R, Rangarajan J, Peng W, Razi N, Gilbert M, Wakarchuk W, Wilson IA, Paulson JC. 2012. Recognition of sialylated poly-N-acetyllactosamine chains on $\mathrm{N}$ - and O-linked glycans by human and avian influenza A virus hemagglutinins. Angewandte Chemie. 51:4860-4863. 